\title{
Cell adhesion and proliferation on chitosan film modified by ion-beam irradiation
}

\author{
K. Takahashi*, K. Uchida*, Y. Suzuki** and H. Yajima* \\ * Graduate School, Tokyo University of Science, Funagawaracho, Ichigaya, Shinjuku, Tokyo, 162-0826, Japan \\ Fax: 81-3-5261-4631 e-mail: j1305705@kagu.tus.ac.jp \\ ** Advanced Development and Supporting Center, RIKEN, 2-1 Hirosawa, Wako, Saitama, 351-0198, Japan \\ Fax: 81-48-462-4623, e-mail: ysuzuki@,riken.jp
}

\begin{abstract}
Recently, chitosan scaffolds with better biocompatibility have been required in various tissue-engineering applications. The aim of this work was to investigate the consequences of ion-beam irradiation on the biological properties of chitosan film, currently used in medical devices. The chitosan films were irradiated with $\mathrm{He}^{+}, \mathrm{Ar}^{+}, \mathrm{Kr}^{+}, \mathrm{O}_{2}^{+}$and $\mathrm{N}_{2}^{+}$at an energy of $150 \mathrm{keV}$ and with fluences of $10^{13}, 10^{14}$ and $10^{15}$ ions $/ \mathrm{cm}^{2}$. Cell adhesion, proliferation and detachment were investigated on chitosan films modified by ion-beam irradiation. Cell culture experiments were carried out with L929 fibroblasts. After $24 \mathrm{~h}$ culturing, cells adhered better on each chitosan film modified by all ion beams with a fluence of $10^{15}$ ions $/ \mathrm{cm}^{2}$ than on non-irradiated chitosan film. Cell proliferation tests after $48 \mathrm{~h}$ culturing indicated that the number of adhering and spreading cells on chitosan film irradiated at $10^{15}$ ions $/ \mathrm{cm}^{2}$ was higher than on non-irradiated films (confirmed by cell adhesion tests). Also, cell attachment strength was increased after ion irradiation with a fluence of $10^{15}$ ions $/ \mathrm{cm}^{2}$. Therefore, these results demonstrated that in-vitro cytocompatibility of the chitosan film was improved by ion-beam irradiation.
\end{abstract}

Keywords: Chitosan, Ion beam, Surface modification Cell adhesion and proliferation, Cell detachment

\section{INTRODUCTION}

Chitosan (poly-1,4-D-glucosamine) is a partially deacetylated from chitin, which is the second most abundant natural polysaccharide and found widely marine crustaceans. Chitosan has been applied in food, agriculture, wastewater treatment and pharmaceutics due to its physiochemical and biological properties. It has gained much attention as a biomaterial in diverse tissue-engineering applications because of its antibacterial and antimicrobial activities, tissue and cell compatibilities, biodegradability by chitosanase and lysozyme, and low cost. In biomedical materials, much interest has been focused on the wound-healing effect, applications as artificial skin substitutes, and tissue-engineering scaffolds. However, many barriers still exist to its broader application due to its physical and chemical limitations. Further study is needed to improve these properties of chitosan film.

Practical applications of polymers strongly depend on their surface properties. Therefore, several modifications of polymer film surfaces, involving plasma treatment, ultraviolet irradiation and ion implantation, have been investigated. Ion implantation has been shown to be a useful technique for modifying the surface properties of polymers. It has been used recently for the surface modification of polymers to improve biocompatibility [1-5].

The aim of the biological evaluations was to perform in vitro cell culture experiments. In this study, the cytocompatibility of chitosan film modified by ion-beam irradiation was evaluated using L929 fibroblast adhesion and proliferation tests. The modified chitosan film should find applications in the biomedical field.

\section{EXPERIMENT}

2.1 Chitosan film preparation

Chitosan was provided from KIMICA Corporation (DDA 80 to $90 \%$, Mw $12.5 \mathrm{kDa})$ Chitosan $(15 \mathrm{mg} / \mathrm{ml})$ was dissolved in $2 \%$ acetic acid. This solution was filtered through a 0.2 $\mu \mathrm{m}$ Millipore membrane, placed into $3.5 \mathrm{~cm}$ polystyrene dishes, and cast at room temperature for $12 \mathrm{~h}$. After complete drying, the resulting films were immersed in a dilute ammonia-methanol solution $\left(15 \mathrm{ml} 30 \% \mathrm{NH}_{4} \mathrm{OH} / 35 \mathrm{ml}\right.$ super pure water $/ 500 \mathrm{ml}$ methanol) for $2 \mathrm{~h}$ to neutralize the acid [6]. After the solution was removed, the films were sterilized by $70 \%$ ethanol for $12 \mathrm{~h}$.

\subsection{Ion-beam irradiation}

The chitosan films were irradiated with $\mathrm{He}^{+}, \mathrm{Ar}^{+}, \mathrm{Kr}^{+}, \mathrm{O}_{2}^{+}$ and $\mathrm{N}_{2}{ }^{+}$ions at an energy of $150 \mathrm{keV}$ with fluences of $10^{13}$, $10^{14}, 10^{15}$ ions $/ \mathrm{cm}^{2}$ at room temperature using the RIKEN $200 \mathrm{keV}$ ion implanter (RIKEN, Saitama, Japan). The target chamber was maintained at a pressure of $10^{-4} \mathrm{~Pa}$ during ion-beam irradiation. For the cell detachment test, ion-beam irradiation was performed using a mask with circular domains with a diameter of $150 \mu \mathrm{m}$. Ion irradiation was performed inside the circular domains to distinguish between non-irradiated and irradiated areas. All irradiated samples were stored in the laboratory atmosphere for at least two weeks before each experiment. Before cell experiments, all samples were sterilized by UV irradiation for $20 \mathrm{~min}$.

\subsection{Cell cultures}

L929 fibroblast cells were grown in Dulbecco's modified Eagles medium (Nissui Pharmaceutical Co., Tokyo, Ltd., Japan) supplemented with $10 \%$ fetal bovine serum (GIBCO, USA), amphotericin B (SIGMA ALDRICH, USA) and kanamycin (nacalai tesque, Japan). They were incubated in a humid atmosphere of $95 \%$ air and $5 \% \mathrm{CO}_{2}$. The culture medium was changed every two days. Cells were routinely passed using a trypsin-EDTA solution. Cultures of $80 \%$ confluent L929 cells were used for all experiments. 

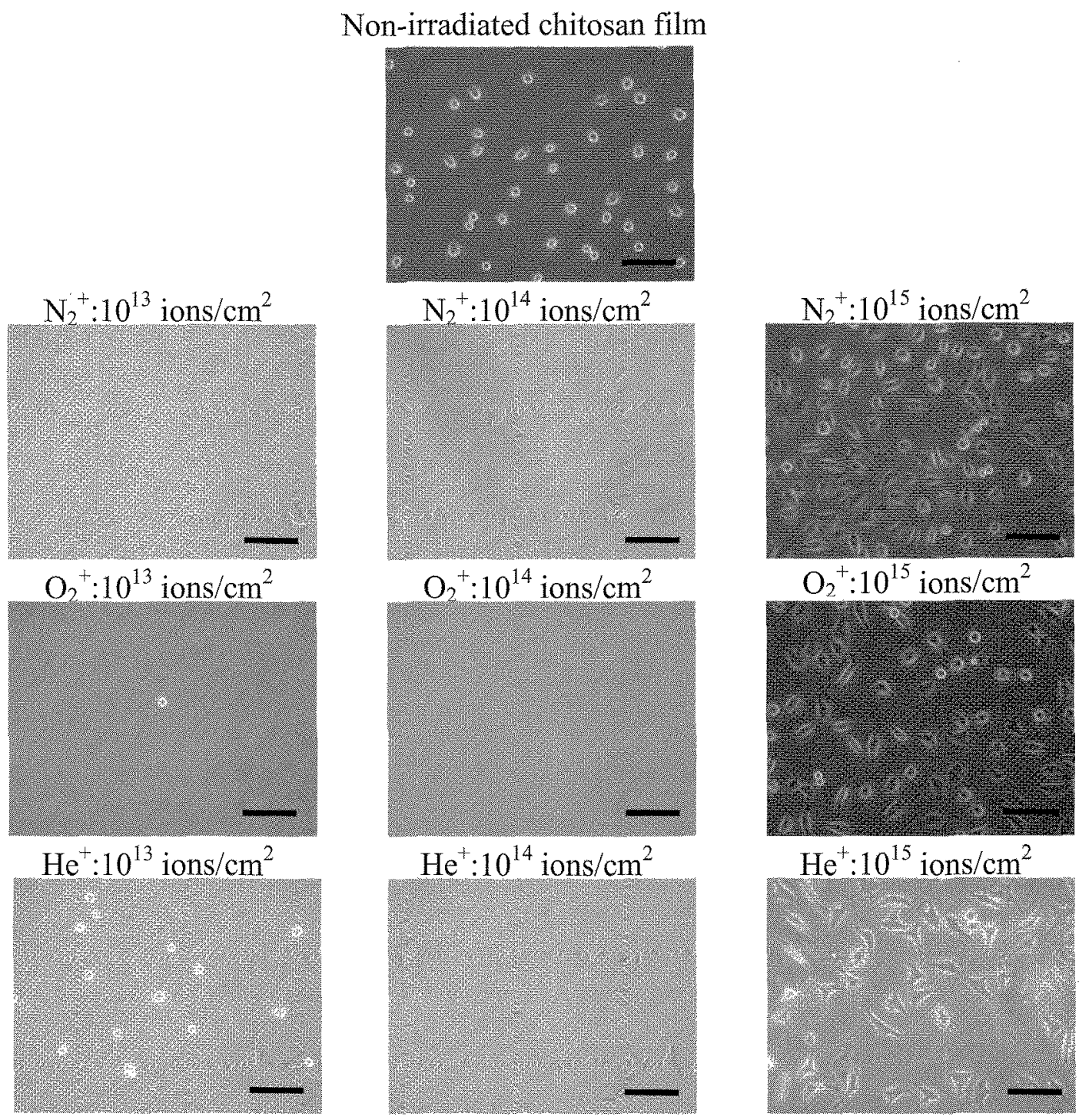

$\mathrm{He}^{+}: 10^{15}$ ions $/ \mathrm{cm}^{2}$
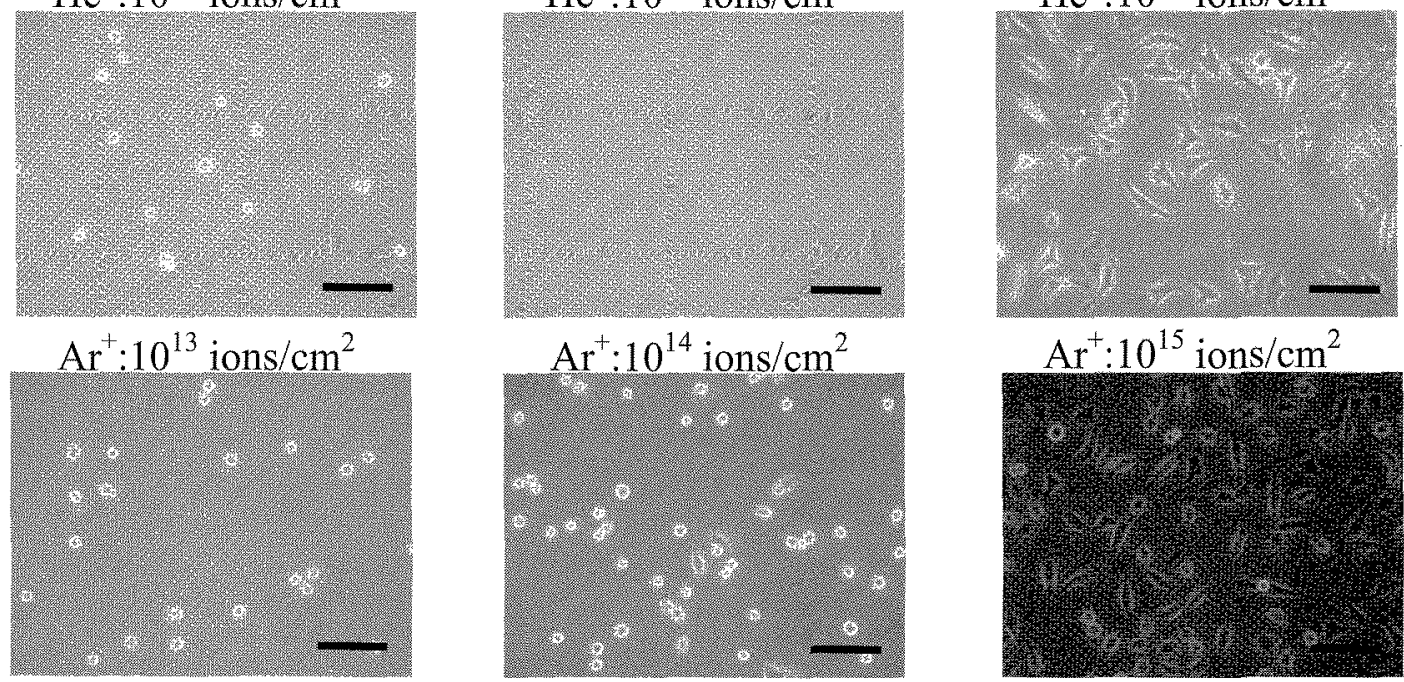

$\mathrm{Kr}^{+}: 10^{13}$ ions $/ \mathrm{cm}^{2}$

$$
\mathrm{Kr}^{+}: 10^{14} \text { ions } / \mathrm{cm}^{2}
$$
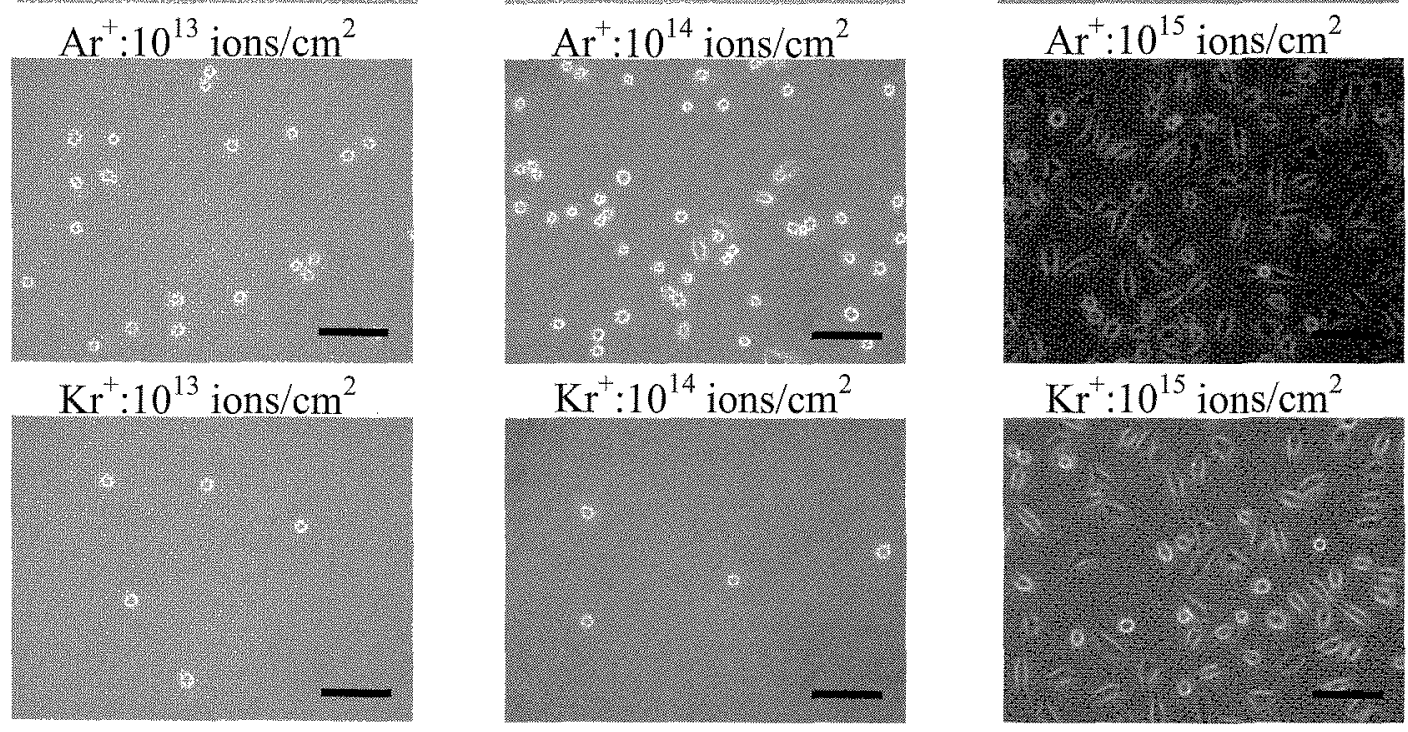

Figure 1. Phase-contrast micrographs of L929 fibroblasts adhering to the chitosan films modified by ion-beam. Scale bar: $100 \mu \mathrm{m}$. 
2.4 Cell adhesion and proliferation tests

Cells were seeded on samples at a density of $10^{4} \mathrm{cells} / \mathrm{cm}^{2}$. They were then incubated for 24 and $48 \mathrm{~h}$ at $37^{\circ} \mathrm{C}$ in a humid atmosphere of $95 \%$ air and $5 \% \mathrm{CO}_{2}$. After the cells were cultured for $24 \mathrm{~h}$ and $48 \mathrm{~h}$, each sample was gently washed with a sterile PBS twice to remove non-adherent cells. The cells adhering to each sample were then photographed by a phase-contrast microscope (Olympus IX71 microscope). The adherent and spread cells were counted using photographs. The average number of adherent and spread cell was determined by measuring at three different points. As a control, non-irradiated chitosan film was prepared.

\subsection{Cell detachment test}

Cell detachment tests were evaluated by trypsin treatment on the cell confluent surface. Trypsinization was performed using trypsin-EDTA solution (Gibco, Canada). Cells were seeded on samples at a density of $10^{4} \mathrm{cells} / \mathrm{cm}^{2}$ and cultured for three days. After three days of culturing, the cell were washed with PBS twice to remove non-adhering cells, and then incubated with trypsin-EDTA solution for $5 \mathrm{~min}$ at $37{ }^{\circ} \mathrm{C}$.

\section{RESULTS AND DISCUSSION \\ 3.1 Cell adhesion}

Figure 1 preasents phase-contrast microscope images of L929 fibroblasts adhering on each sample after $24 \mathrm{~h}$ culturing. In the initial studies presented here, we focused on the number of adhering cells per unit surface area. For $\mathrm{N}_{2}^{+}$and $\mathrm{O}_{2}^{+}$irradiation, no cell adhesion was observed on the chitosan films at $10^{13}$ and $10^{14}$ ions $/ \mathrm{cm}^{2}$. However, many cells were observed adhering to the films irradiated at $10^{15}$ ions $/ \mathrm{cm}^{2}$. On the $\mathrm{He}^{+}$ion modified specimens, round and spread cells were observed adhering to the film irradiated at $10^{13}$ ions $/ \mathrm{cm}^{2}$, but not to the film irradiated at $10^{14} \mathrm{ions} / \mathrm{cm}^{2}$. For $\mathrm{Ar}^{+}$and $\mathrm{Kr}^{+}$irradiation, little cellular adhesion was observed on the samples irradiated at $10^{13}$ and $10^{14}$ ions $/ \mathrm{cm}^{2}$. However, cell adhesion was promoted on the chitosan film modified at $10^{15}$ ions $/ \mathrm{cm}^{2}$. Rare gas ion irradiation at $10^{15}$ ions $/ \mathrm{cm}^{2}$ enhanced cell adhesion with increasing gas ion mass.

It was very clear that cell adhesion was enhanced on all surfaces modified by $\mathrm{He}^{+}, \mathrm{Ar}^{+}, \mathrm{Kr}^{+}, \mathrm{N}_{2}^{+}$and $\mathrm{O}_{2}{ }^{+}$beams at $10^{15}$ ions $/ \mathrm{cm}^{2}$ as compared with the control chitosan film.

\subsection{Cell proliferation}

Cell proliferation in response to different surface irradiation by ion beams was assessed using photographs at $24 \mathrm{~h}$ and 48 $\mathrm{h}$ after seeding $\mathrm{L} 929$ fibroblasts. The spread cells were counted in three random areas. Figure 2 presents the number of spread cells after $24 \mathrm{~h}$ and $48 \mathrm{~h}$ incubation. Cells that adopted a flattened, polygonal shape with filopodia- and lamellipodia-like extensions were regarded as spreading cells. The number of spreading cells increased. However, as after $24 \mathrm{~h}$ culturing, spreading cells were not observed on the specimens modified by $\mathrm{N}_{2}^{+}$and $\mathrm{O}_{2}^{+}$ion beams at $10^{13}$ and $10^{14} \mathrm{ions} / \mathrm{cm}^{2}$.

The total number of cells on the films irradiated at $10^{15}$ ions $/ \mathrm{cm}^{2}$ for all ions was consistently higher than that of the control film. Compared to the control, twice as many spread cells were observed on the chitosan films modified for all ions after $48 \mathrm{~h}$ culturing. The cell proliferation rates on the samples modified at $10^{15}$ ions $/ \mathrm{cm}^{2}$ were similar. These results demonstrated that initial cell proliferation is related to cell adhesion.

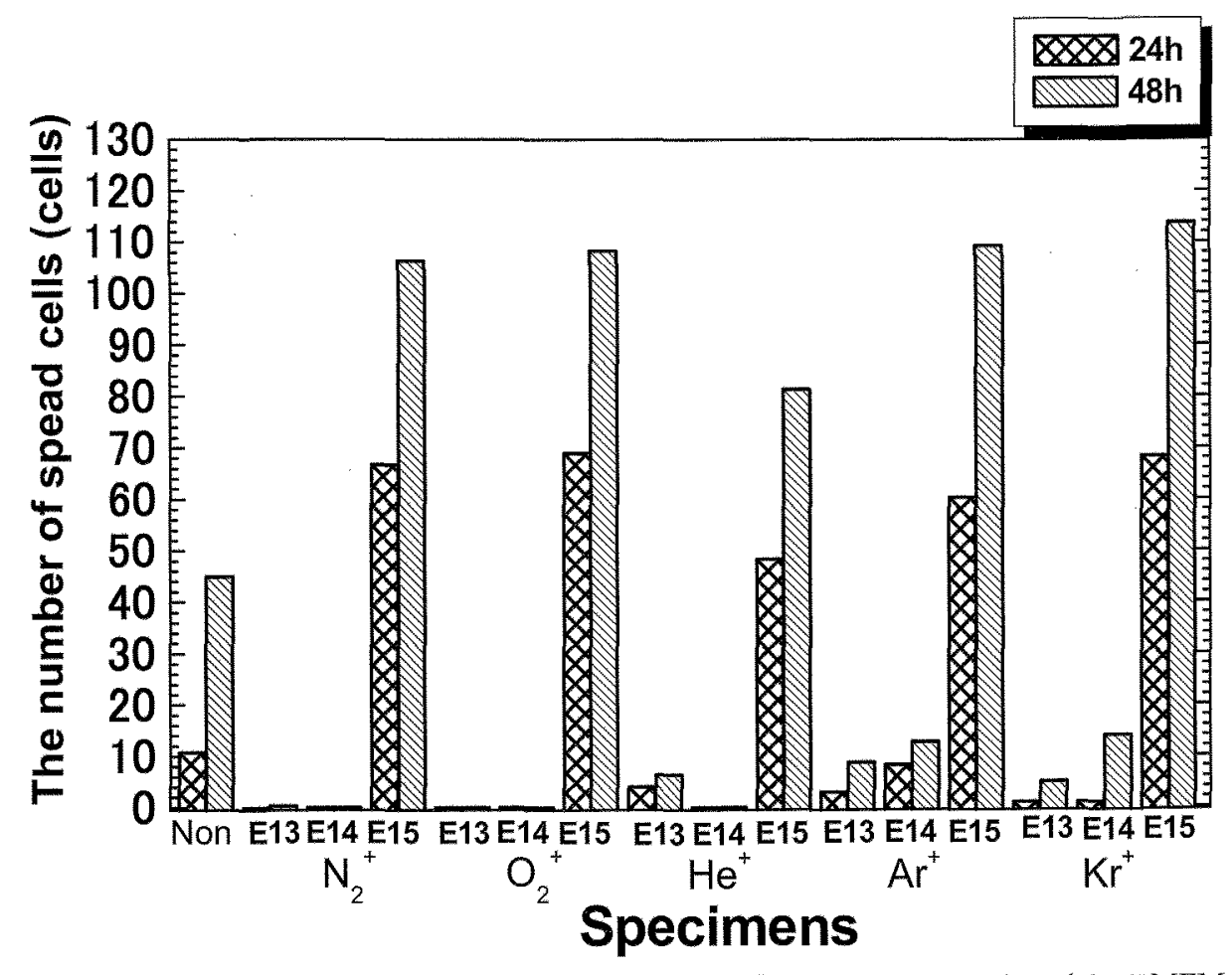

Figure 2. Cell proliferation versus specimens. L929 fibroblasts were cultured in DMEM

(10\% FBS) for $24 \mathrm{~h}$ and $48 \mathrm{~h}$. 

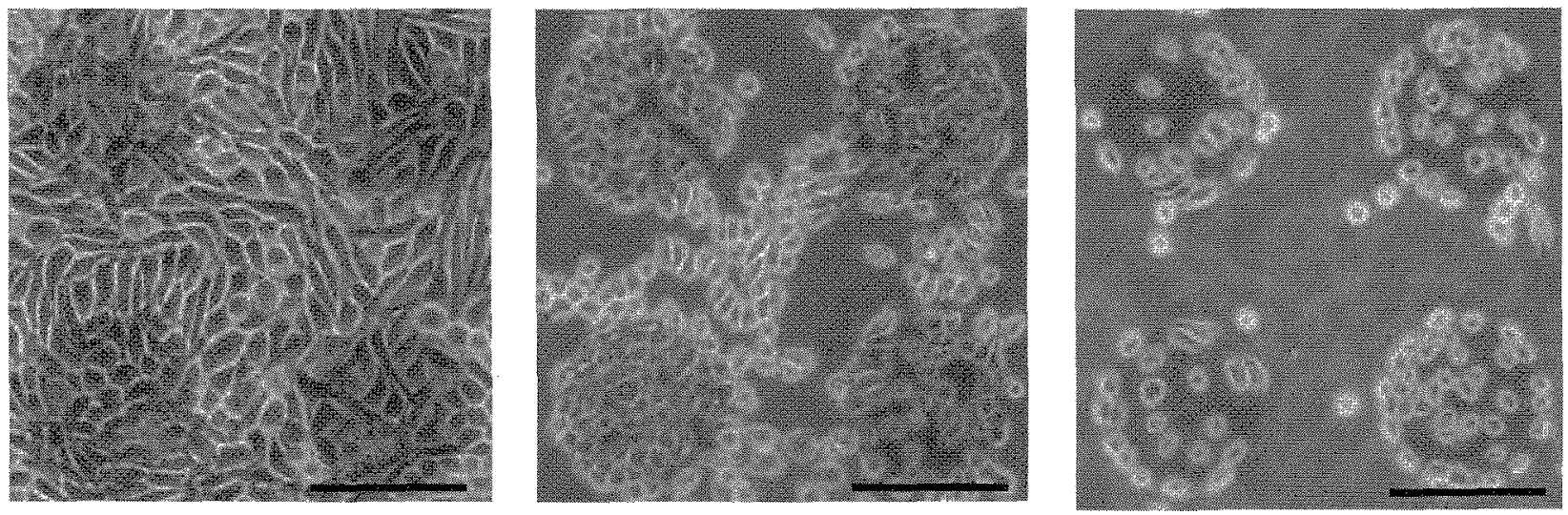

Figure 3. Phase contrast microscopy images of L929 fibroblasts cultured on $\mathrm{Kr}^{+}$ion irradiated chitosan films with a

fluence of $10^{15}$ ions $/ \mathrm{cm}^{2}$ (a) before trypsin treatment and after treatment at (b) 3 min and (c) $5 \mathrm{~min}$. Scale bar:150 $\mu \mathrm{m}$.

\subsection{Cell detachment}

After three days of culturing, the cells were confluent on the chitosan film patterned-irradiated by a $\mathrm{Kr}^{+}$ion beam with a fluence of $10^{15}$ ions $/ \mathrm{cm}^{2}$ (Figure 3-(a)). Figure 3-(b) and (c) present phase-contrast microscope observations of cell shapes of the cells after 3 min and 5 min trypsin treatment at $37{ }^{\circ} \mathrm{C}$. Cells began to detach from the non-irradiated region (outside the circular domain) after 3 min. After $5 \mathrm{~min}$, no attached cells were observed on the non-irradiated region. However, the attached cells remained on the irradiated region (inside the circular domain) with $10^{15}$ ions $/ \mathrm{cm}^{2}$. For all other ion species, this tendency is largely similar to $\mathrm{Kr}^{+}$ion irradiation. All the cells on every sample were detached from dishes within 10 minutes. These results indicated that cell attachment strength was increased by ion-beam irradiation with a fluence of $10^{15}$ ions $/ \mathrm{cm}^{2}$.

\section{CONCLUSION}

The present study focused on cell adhesion and initial proliferation on chitosan film modified by $\mathrm{He}^{+}, \mathrm{Ar}^{+}, \mathrm{Kr}^{+}, \mathrm{N}_{2}^{+}$ and $\mathrm{O}_{2}^{+}$ion beams. Cellular adhesion was significantly promoted on the surface modified by ion beams with a fluence of $10^{15}$ ions $/ \mathrm{cm}^{2}$ for all ion species. Cytocompatibility on the $\mathrm{Kr}^{+}$irradiated chitosan film is the highest among all specimens. The difference in cell adhesion is related to surface physicochemical properties. Cell adhesion seems to be related to chemical functional groups, wettability, morphology and surface potential. Ion irradiation onto a polymer surface induces amorphous carbon phase and new functional groups. Additionally, it has been reported that the amorphous carbon phase promotes cell adhesion and proliferation $[7,8]$. Therefore, in this ion-beam irradiation onto chitosan film, we believe that the amorphous carbon phase and new functional groups produced by ion-beam irradiation enhanced cell adhesion and initial proliferation. The extracellular matrix (ECM), which is a cell-adhesive protein (e.g. fibronectin, laminin), promotes and regulates cell adhesion and proliferation. Consequently, it is presumed that the amount of ECM adsorption onto the chitosan film modified at $10^{15}$ ions $/ \mathrm{cm}^{2}$ is higher than that onto non-irradiated film. Further study is needed to evaluate the amount of ECM adsorption onto each specimen to investigate the relation between surface properties and cell adhesion. These results demonstrate that chitosan films modified by ion beams with a fluence of $10^{15}$ ions $/ \mathrm{cm}^{2}$ are useful and promising biomaterials. Also, a non cell adhesive surface was observed on the modified chitosan film, for example, by $\mathrm{N}_{2}{ }^{+}$ ion-beam with a fluence of $10^{13}$ ions $/ \mathrm{cm}^{2}$. In conclusion, we can control cell adhesive and non-adhesive properties on the modified chitosan film by selecting the ion species and fluences.

\section{REFERENCES}

[1] Y. Suzuki, M. Kusakabe, J.-S. Lee, M. Kaibara, M. Iwaki and H. Sasabe, Nucl. Instrum. Methods Phys. Res. B65, 142-147 (1992)

[2] Y. Suzuki, H. Iwata, A. Nakao, M. Iwaki, H. Sasabe, S. Kaneko, H. Nakajima and M. Kusakabe, Nucl. Instrum. Methods Phys. Res. B127/128, 1019-1022 (1997)

[3] K.Kurotobi, M. Kaibara, Y. Suzuki, M. Iwaki and H. Nakajima, Nucl. Instrum. Methods Phys. Res. B175/177, 791-796(2001)

[4] T. Yotoriyama, A. Nakao, Y. Suzuki, T. Tsukamoto and M. Iwaki, Nucl. Instrum. Methods Phys. Res. B242, 51-54 (2006) [5] N. Takahashi, Y. Suzuki, H. Ujiie, T. Hori, M. Iwaki and T.Yamada, Nucl. Instrum. Methods Phys. Res. B242, 61-64 (2006)

[6] C. Chatelet, O. Damour and A. Domard Biomaterials, 22, 261-268 (2001)

[7] B. Pignataro, E. Conte, A. Scandurra and G. Marletta, Biomaterials, 18, 1461-1470 (1997)

[8] C. Satrinano, S. Carnazza, G. Marletta and E. Conte, Nucl. Instrum. Methods Phys. Res. B208, 287-293 (2003)

(Received December 10, 2006;Accepted May 15, 2007) 